\title{
9 - Outros recursos de expressão do aspecto
}

\author{
Luiz Carlos Travaglia
}

\section{SciELO Books / SciELO Livros / SciELO Libros}

TRAVAGLIA, L.C. Outros recursos de expressão do aspecto. In: O aspecto verbal no português: a categoria e sua expressão [online]. 5th ed. Uberlândia: EDUFU, 2016, pp. 253-274. ISBN: 978-655824-014-3. https://doi.org/10.7476/9786558240143.0011.

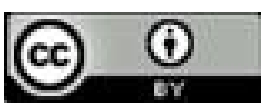

All the contents of this work, except where otherwise noted, is licensed under a Creative Commons Attribution 4.0 International license.

Todo o conteúdo deste trabalho, exceto quando houver ressalva, é publicado sob a licença Creative Commons Atribição $\underline{4.0}$.

Todo el contenido de esta obra, excepto donde se indique lo contrario, está bajo licencia de la licencia $\underline{\text { Creative Commons }}$ Reconocimento 4.0. 


\section{9 - Outros recursos de expressão do aspecto}

\section{1 - Semantema do Verbo}

Ao falarmos sobre a expressão do aspecto pelas flexões verbais e pelas perífrases, falamos sobre numerosos casos em que o aspecto expresso sofre a influência do semantema verbal, que não cabe repetir aqui. Vimos que o fato do verbo ser télico ou atélico; ser um verbo de processo, de evento ou de estado (ou, de modo mais amplo, de situação estática); indicar uma situação que aceita ou não descontinuidade afeta o aspecto expresso por uma dada flexão verbal ou perífrase. Estes diferentes tipos de verbos permitem explicar a presença de diferentes noções aspectuais em casos formalmente idênticos.

Acrescentaremos algo a dois dos casos já citados. Comrie (1976, p.50, 51) diz que, quando temos perfectivo + estado, há sempre uma referência ao começo ou término do estado. Em Português, podemos dizer que, quando temos um verbo de situação estática (seja estado ou não) com aspecto perfectivo, temos sempre uma referência ao término da situação, pois neste caso temos sempre aspecto acabado. É isto que explica o fato dos pretéritos perfeito e mais-que-perfeito do indicativo marcarem sempre o aspecto acabado, com os verbos de estado e estáticos em geral (cf. itens 7.3 e 7.4).

Em segundo lugar, queremos ressaltar que, quando temos um verbo de evento com uma forma durativa, se o verbo não muda de sentido (como no exemplo 117), nem temos os efeitos de significado observados nas frases (114) a (116); forçosamente teremos uma interpretação iterativa ${ }^{1}$, embora nem sempre possamos falar em aspecto iterativo. Alguns exemplos deste fato podem ser vistos no estudo da perífrase vir + gerúndio (cf. item 8.5.4., exemplos 909 a 911) e também em outros casos, como com as perífrases de continuar e prosseguir (cf. item 8.9, onde afirmamos que aspecto durativo + evento $=$ iteratividade).

\footnotetext{
${ }^{1}$ Verkuyl (1972) observou o mesmo fato para o alemão. (VERKUYL, H. J. On the compositional nature of the aspects. Dordrecht: D. Reidel, 1972. (Foundations of language, 15).).
} 
Em frases do tipo de (1.273), com a duração marcada por adjunto adverbial, temos também a interpretação iterativa.

\subsection{Laura abriu a porta durante duas horas.}

Como esta não é a maneira mais natural de expressar a iteração, sempre que possível o falante muda o significado do verbo para evitar a interpretação iterativa. É o que acontece em (1.274), onde a tendência é dar à frase o significado de que a pessoa ficou com o rádio ligado durante meia hora, e não que ficou ligando-o e desligando-o durante a meia hora.

\subsection{Elvira ligou o rádio meia-hora.}

Além do tipo de influência do semantema do verbo a que aludimos acima, temos os casos em que o aspecto é expresso pelo radical do próprio verbo. Os verbos que expressam aspecto pelo radical são sempre verbos que, pelo menos quando estão nesta função, não indicam situações propriamente ditas. São verbos que apenas introduzem certos matizes semânticos e/ou marcam aspecto, e sempre servem de suporte às categorias verbais de tempo, modo, número e pessoa, enquanto as situações são indicadas: a) por outro verbo (constituindo então uma perífrase); b) por substantivos que aparecem como seus sujeitos ou objetos; ou adjetivos (se a situação for um estado ou condição do ser). Quando a situação é um estado pode ser representada também pelo verbo, normalmente no particípio.

Já explicamos no item 4.2.4, porque os verbos indicadores de processos e eventos não marcam aspecto durativo e pontual. No item 4.2.14, explicamos porque os verbos indicadores de situações inceptivas e terminativas não marcam aspecto inceptivo e terminativo. As colocações que fazemos parecem suficientes para deixar claro que as colocações de Câmara Jr. sobre a expressão do aspecto pelo semantema do verbo (cf. item 1.3.8) não são válidas, de acordo com nosso modo de ver o aspecto. Nestes casos, as situações é que são durativas, pontuais, inceptivas ou terminativas, o que é diferente de apresentar uma situação como tendo duração contínua limitada, sem duração, em seu momento de início ou término, ou em seus primeiros ou últimos momentos.

Abaixo apresentamos um quadro com os verbos que expressam aspecto pelo semantema, o aspecto indicado, os elementos que normalmente indicam a situação e as condições em que o verbo expressa o aspecto. Estas condições dirão respeito apenas aos casos em que a situação é expressa por substantivo ou adjetivo, uma vez que para as perífrases já fizemos o comentário no capítulo 8. Os exemplos dados estão no mesmo caso. 


\begin{tabular}{|c|c|c|c|}
\hline \multicolumn{4}{|c|}{ QUADRO VI } \\
\hline VERBOS & $\begin{array}{l}\text { ASPECTOS QUE } \\
\text { EXPRESSAM }\end{array}$ & $\begin{array}{l}\text { ELEMENTOS } \\
\text { INDICADORES } \\
\text { DA SITUAÇÃO }\end{array}$ & $\begin{array}{c}\text { CONDIÇÕES EM } \\
\text { QUE O ASPECTO } \\
\text { É EXPRESSO }\end{array}$ \\
\hline Estar & $\begin{array}{l}\text { Imperfectivo, cur- } \\
\text { sivo, não acabado } \\
\text { e durativo }\end{array}$ & Verbo ou adjetivo & $\begin{array}{l}\text { Em todas as flexões } \\
\text { verbais, exceto nos } \\
\text { pretéritos perfeito e } \\
\text { mais-que-perfeito do } \\
\text { indicativo, em que } \\
\text { só marca o durativo. } \\
\text { Exatamente como } \\
\text { na perífrase de es- } \\
\text { tar + particípio (item } \\
8.3 .3 \text {, em que vimos } \\
\text { que o particípio vale } \\
\text { por um adjetivo). } \\
\text { Exemplos: (1.275) } \\
\text { a (1.282), exceto as } \\
\text { frase b. }\end{array}$ \\
\hline Andar & $\begin{array}{l}\text { Imperfectivo, cur- } \\
\text { sivo, não acabado } \\
\text { e durativo }\end{array}$ & $\begin{array}{l}\text { Adjetivo ou equiva- } \\
\text { lente (como o par- } \\
\text { ticípio verbal, por } \\
\text { exemplo) }\end{array}$ & $\begin{array}{l}\text { Quando funciona } \\
\text { como verbo rela- } \\
\text { cional ou de ligação } \\
\text { em todas as flexões } \\
\text { verbais, exceto nos } \\
\text { pretéritos perfeito e } \\
\text { mais-que-perfeito do } \\
\text { indicativo, em que } \\
\text { só marca o durativo } \\
\text { e nas flexões verbais } \\
\text { de valor temporal } \\
\text { futuro, em que não } \\
\text { expressa nenhum } \\
\text { aspecto. Exemplos: } \\
(1.275 b),(1.279 b) \text { e } \\
(1.281 b) \text {. }\end{array}$ \\
\hline Viver & Habitual & Verbo ou adjetivo & $\begin{array}{l}\text { Nas condições já es- } \\
\text { pecificadas em } 8.6 .3 \text {, } \\
\text { quando falávamos } \\
\text { da perífrase "viver } \\
\text { + particípio". Exem- } \\
\text { plos: }(961),(1283) \text { e } \\
(1.284) \text {. }\end{array}$ \\
\hline Costumar & Habitual & Verbo & Veja item 8.6.4 \\
\hline Usar & Habitual & Verbo & Veja item 8.6.5 \\
\hline
\end{tabular}


Continuação da página 255

\begin{tabular}{|c|c|c|c|}
\hline VERBOS & $\begin{array}{c}\text { ASPECTOS QUE } \\
\text { EXPRESSAM }\end{array}$ & $\begin{array}{l}\text { ELEMENTOS } \\
\text { INDICADORES } \\
\text { DA SITUAÇÃO }\end{array}$ & $\begin{array}{c}\text { CONDIÇÕES EM } \\
\text { QUE O ASPECTO } \\
\text { É EXPRESSO }\end{array}$ \\
\hline Ficar & Iterativo & Verbo & $\begin{array}{l}\text { Veja item } 8.7 \text {, } \\
\text { quando o verbo } \\
\text { ficar tem o terceiro } \\
\text { significado. }\end{array}$ \\
\hline Ficar & Durativo & Verbo ou adjetivo & $\begin{array}{l}\text { Nas condições já } \\
\text { especificadas no } \\
\text { item } 8.7 \text {, quando o } \\
\text { verbo "ficar" tem } \\
\text { o primeiro signi- } \\
\text { ficado. Exemplos } \\
\text { (1.285) a (1.287). }\end{array}$ \\
\hline Continuar & $\begin{array}{l}\text { Começado, } \\
\text { durativo }\end{array}$ & $\begin{array}{l}\text { Verbo ou } \\
\text { substantivo }\end{array}$ & $\begin{array}{l}\mathrm{N} \text { a s m e s m a s } \\
\text { condições já espe- } \\
\text { cificadas em } 8.9 \text {. } \\
\text { Exemplos: }(1.288) \\
\text { a (1.291). }\end{array}$ \\
\hline Prosseguir & $\begin{array}{l}\text { Começado, } \\
\text { durativo }\end{array}$ & $\begin{array}{l}\text { Verbo ou } \\
\text { substantivo }\end{array}$ & $\begin{array}{l}\mathrm{N} \text { a s m e s m a s } \\
\text { condições já espe- } \\
\text { cificadas em } 8.9 \text {. } \\
\text { Exemplos: }(1.292) \\
\text { a (1.295). }\end{array}$ \\
\hline Acabar & Terminativo & $\begin{array}{l}\text { Verbo ou } \\
\text { substantivo }\end{array}$ & 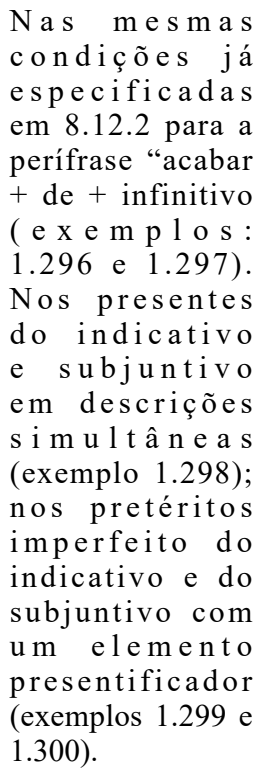 \\
\hline
\end{tabular}




\begin{tabular}{|c|c|c|c|}
\hline VERBOS & $\begin{array}{c}\text { ASPECTOS QUE } \\
\text { EXPRESSAM }\end{array}$ & $\begin{array}{l}\text { ELEMENTOS } \\
\text { INDICADORES } \\
\text { DA SITUAÇÃO }\end{array}$ & $\begin{array}{l}\text { Continuação da página } 2 \\
\text { CONDIÇÕES EM } \\
\text { QUE O ASPECTO } \\
\text { É EXPRESSO }\end{array}$ \\
\hline Terminar & Terminativo & $\begin{array}{l}\text { Verbo ou } \\
\text { substantivo }\end{array}$ & $\begin{array}{l}\text { Nas mesmas } \\
\text { condiçõ j já } \\
\text { e specificadas } \\
\text { em } 8.13 .2 \text { para a } \\
\text { perífrase "terminar } \\
+ \text { de + infinitivo". } \\
\text { Exemplos (1.301) } \\
\text { a (1.304). }\end{array}$ \\
\hline Começar, principiar & Inceptivo & $\begin{array}{l}\text { Verbo ou } \\
\text { Substantivo }\end{array}$ & $\begin{array}{l}\text { Nas mesmas } \\
\text { condiçó es já } \\
\text { especificadas em } \\
8.14 .1 \text { para as } \\
\text { perífrases "começar } \\
+ \text { a + infinitivo" } \\
\text { e "principiar + } \\
\text { a + infinitivo". } \\
\text { Exemplos: (1.305) } \\
\text { a (1.309). }\end{array}$ \\
\hline $\begin{array}{l}\text { Iniciar, } \\
\text { iniciar-se }\end{array}$ & Inceptivo & Substantivo & $\begin{array}{l}\text { Nas mesmas } \\
\text { c o n d i ç o e s } \\
\text { especificadas } \\
\text { para "começar" } \\
\text { e "principiar", } \\
\text { acima. Exemplos: } \\
(1.310) \text { a (1.315). }\end{array}$ \\
\hline Ser & Indeterminado & $\begin{array}{l}\text { Adjetivo ou } \\
\text { equivalente e } \\
\text { substantivo em } \\
\text { função atributiva }\end{array}$ & $\begin{array}{l}\text { Com todas as } \\
\text { flexões verbais. } \\
\text { Ex e m p lo s : } \\
(1.316) \text { a }(1.321) \text {. } \\
\text { Para a perífrase } \\
\text { "ser + de + } \\
\text { infinitivo", veja } \\
8.15 .3 \text {. }\end{array}$ \\
\hline
\end{tabular}


Exemplos:

1.275. a - Seu irmão está elegante.

b - Seu irmão anda triste ultimamente.

1.276. Na festa ele estava todo feliz.

1.277. O vaso estará lindo quando você vier buscá-lo.

1.278. A casa estaria suja se eu não a tivesse limpado.

1.279. a - Embora Joel esteja tão amável, não consigo acreditar em sua amabilidade.

b - Embora Joel ande tão amável, não consigo acreditar em sua amabilidade.

1.280. Estar apto para o trabalho é um dever de vocês, o que vamos verificar é quem está mais apto.

1.281. a - Essa casa esteve limpa.

b - João andou preocupado estes dias.

1.282. O artista estivera inigualável em sua apresentação e se sentia satisfeito.

Em (1.275) a (1.280), temos os aspectos imperfectivo, cursivo, não acabado, durativo; em (1.281) e (1.282), o perfectivo, o acabado e o durativo. Parece haver restrição ao uso de "andar" como relacional e marcador de aspecto em vários tempos flexionais.

1.283. Mariazinha vivia suja. (imperfectivo, não acabado, habitual).

1.284. Embora meu irmão viva impaciente com os funcionários não os trata mal. (imperfectivo, não acabado, habitual).

1.285. Se eu lhe der uma bala, você fica bonzinho até sua mãe voltar? (durativo).

1.286. Por sua causa, Laura ficou triste o dia todo. (perfectivo, durativo).

1.287. Naquele dia, ele me disse que ficasse pura, como eu era, por toda a vida. (durativa).

1.288. A festa continua animada. (imperfectivo, cursivo, começado, durativo).

1.289. Como os dois países não assinaram o tratado de paz, a guerra continua. (imperfectivo, cursivo, começado, durativo).

1.290. A disputa continuou até à tarde. (começado, durativo - estes aspectos se referem à S.N. expressa pelo substantivo disputa; a S.R. de "continuar a disputa" tem aspecto perfectivo). 
1.291. Embora Laerte continue triste, já está mais conformado. (imperfectivo, cursivo, não acabado, durativo).

1.292. O torneio prossegue sem muitas novidades. (imperfectivo, cursivo, não acabado, durativo).

1.293. Quando voltamos à sala, a discussão prosseguia. (imperfectivo, cursivo, não acabado, durativo).

1.294. A disputa prosseguiu até tarde. (idem ao exemplo 1.290).

1.295. Embora a guerra prossiga, há esperanças de que os dois países façam um acordo de paz. (imperfectivo, cursivo, não acabado, durativo).

1.296. César está acabando o trabalho. (imperfectivo, terminativo, não acabado).

1.297. Se você demorar muito o baile estará acabando quando chegarmos lá. (imperfectivo, terminativo, não acabado).

1.298. A corrida acaba (= está acabando) numa disputa acirrada pelo primeiro lugar. (imperfectivo, terminativo, não acabado).

1.299. Quando entramos no campo a partida acabava. (imperfectivo, terminativo, não acabado).

1.300. Embora o baile acabasse quando chegamos, ainda pudemos nos divertir um pouco. (imperfectivo, terminativo, não acabado).

1.301. - O que você está fazendo?

- Termino o trabalho que tenho de entregar amanhã. (imperfectivo, terminativo, não acabado).

1.302. Quando chegamos à fazenda, os peões terminavam a colheita. (imperfectivo, terminativo, não acabado).

1.303. Embora a procura esteja terminando, ainda não encontramos nenhum espécimen desconhecido. (imperfectivo, terminativo, não acabado).

1.304. A discussão terminou quando soou a campainha, anunciando o final da aula. (terminativo e acabado - estes aspectos se referem à S.N. expressa pelo substantivo discussão. A situação de "terminar a discussão" tem aspectos perfectivo e acabado).

1.305. A festa começa e todos já demonstram muita animação. (imperfectivo, inceptivo, começado).

1.306. Quando fomos à oficina Hugo começava o trabalho. (imperfectivo, inceptivo, começado).

1.307. A guerra começou no dia 3 de julho de 1972.

a - S.R.: começar a guerra - perfectivo, acabado.

b - S.N.: expressa pelo substantivo guerra - começado, inceptivo. 
1.308. Quando chegarmos à fazenda, o pessoal estará começando a plantação. (imperfectivo, inceptivo, começado).

1.309. Embora a greve apenas começasse, já se percebia que não duraria muito. (imperfectivo, inceptivo, começado).

1.310. O torneio inicia-se e há grande expectativa entre as diversas equipes. (imperfectivo, inceptivo, começado).

1.311. Há dois dias, os presidentes dos clubes iniciavam as conversações que resultaram no documento apresentado hoje à CBD. (imperfectivo, inceptivo, começado).

1.312. A festa se iniciou exatamente às quatorze horas. a - S.R.: iniciar a festa - perfectivo, acabado. b - S.N.: expressa pelo substantivo festa - inceptivo, começado.

1.313. Às dez horas o debate estará se iniciando e deverá acabar até o meio dia. (imperfectivo, inceptivo, não acabado).

1.314. Embora o inquérito apenas se inicie, muita gente já está em dificuldades para provar sua inocência. (imperfectivo, inceptivo, começado).

1.315. Mesmo que a epidemia estivesse se iniciando, seria muito difícil controlá-la. (imperfectivo, inceptivo, começado).

1.316. Maria é bondosa. (imperfectivo, não acabado, indeterminado).

1.317. João era feliz quando morava aqui. (imperfectivo, não acabado, indeterminado).

1.318. Isá foi professor a vida toda. (perfectivo, acabado, indeterminado).

1.319. Meu filho será um agricultor como eu. (indeterminado).

1.320. Embora Rui seja alto, não se aproveita disso no jogo. (imperfectivo, não acabado, indeterminado).

1.321. Se Jorge for realmente um médico, não deixará de socorrer você. (imperfectivo, não acabado, indeterminado).

OBS. - O verbo ser marca o aspecto indeterminado, porque expressa sempre estado permanente, isto é, de duração contínua ilimitada.

Os exemplos apresentados neste item nos mostram que, mesmo quando a situação é expressa por um substantivo ou adjetivo, o aspecto se concentra no verbo, mesmo que este tenha a única função de servir de suporte às categorias verbais, sem indicar qualquer situação. 
É interessante observar ainda que não temos aspectos inceptivo e terminativo com verbos de estado. Isto parece se dar porque a língua expressa o início dos estados lexicalmente por outros verbos (como adoecer, sarar, endurecer, emagrecer etc.), ou pelo verbo "ficar + estado" (ficar doente, ficar feliz etc.). Quanto ao final do estado deve-se ter em mente o que comentamos logo após o quadro II, no item 3.2, onde dizemos que o final de um estado é sempre o início de outro e que a língua centra-se no estado que começa. A única possibilidade de termos inceptivo e terminativo com verbos de estado seria em frases do tipo de (1.322) e (1.323) abaixo.

1.322. João começa a estar doente. (feliz, preocupado, etc.). (imperfectivo, inceptivo, não acabado).

1.323. a - * João termina de estar doente. (feliz, preocupado, etc.). b - ?*João está deixando de estar doente. (feliz, preocupado, etc.).

Embora tais frases sejam possíveis pelo código linguístico do Português, os falantes veem frases do tipo de (1.323) como inaceitáveis e, embora achem possíveis frases como (1.322), afirmam que não as usariam, porque não são usadas habitualmente. As frases inceptivas com "ser" são mais aceitáveis e inclusive usadas (exemplo 1.324), mas as terminativas continuam inaceitáveis (exemplo 1.325 a).

A restrição parece ser porque um estado, bem como outras situações estáticas do tipo de amar e respirar (exemplo $1.325 \mathrm{c}$ ) não terminam propriamente, mas cessam sem atingir um ponto terminal. Daí termos frases mais aceitáveis quando empregamos perífrases de valor mais cessativo (cf. nota 135). Exemplos (1.325 b) e $(1.325$ d). Todavia as frases com outros verbos de estado que não o verbo "ser" continuam muito estranhas (exemplo $1.323 \mathrm{~b}$ ).

1.324. Raul começa a ser feliz. (imperfectivo, não acabado, inceptivo).

1.325. a - * Raul termina de ser feliz. (ou "* está terminando de ser feliz").

b - Raul está deixando de ser feliz. (imperfectivo, não acabado, terminativo).

c - * Raul termina de respirar. (ou “* está terminando de respirar").

d - Raul está deixando de respirar. (imperfectivo, não acabado, terminativo). 


\section{2 - Adjuntos ADVERbiais}

Não há qualquer dúvida quanto ao fato de que os adjuntos adverbiais têm muito a ver com o aspecto. Alguns estudiosos notaram esta relação. Assim por exemplo, Verkuyl (1.972, p.8) afirma que qualquer tentativa de descrever sentenças que contêm advérbios de tempo, não pode ignorar o aspecto. Castilho (1.967) aponta numerosos exemplos em que o adjunto adverbial seria o responsável pelo aspecto presente na frase. Este autor anota ainda que os adjuntos adverbiais envolvidos na expressão do aspecto são sempre temporais.

No estudo da expressão do aspecto pelas flexões verbais e pelas perífrases, arrolamos os principais casos de atuação dos adjuntos adverbiais neste particular. Desnecessário, pois, repeti-los aqui. O que faremos será, tão somente, apresentar alguns delineamentos gerais.

Os aspectos em cuja expressão os adjuntos adverbiais atuam são o iterativo, o habitual, o durativo, o inceptivo, o terminativo e o acabado.

Observamos que os adjuntos adverbiais, envolvidos na expressão do aspecto em Português, exercem sempre uma de três funções:

a. evitar ambiguidades;

b. marcar o aspecto por si ou em combinação com outro elemento;

c. reforçar um aspecto expresso por outro elemento, tornando-o mais patente.

Apenas para facilidade do leitor, remeter-nos-emos a alguns dos casos já estudados. O adjunto adverbial evita ambiguidade, por exemplo, na expressão do habitual pelo pretérito imperfeito do indicativo (cf. comentários em torno dos exemplos 364 a 369).

$\mathrm{O}$ adjunto adverbial marca o aspecto por si, por exemplo, quando marca o acabado com o presente do indicativo (cf. o exemplo 318 e comentários); ou quando marca o durativo (cf. exemplos 354 a 356 e comentários), o iterativo (exemplos 358 e 359) ou o habitual (exemplo 360) com o pretérito perfeito do indicativo. Em combinação com outro elemento o adjunto adverbial marca, por exemplo, o aspecto inceptivo e terminativo, respectivamente com as perífrases "começar + a + infinitivo" e "terminar + de + infinitivo" nos futuros e nos pretéritos perfeito e mais-que-perfeito do indicativo (cf. exemplos 1.171 a 1.175 , $1.176,1.200$ a 1.202, 1.204 e comentários).

É comum o adjunto adverbial reforçar o aspecto já expresso por outro 
elemento. Isto ocorre, por exemplo, com os aspectos iterativo e habitual expresso pelo pretérito imperfeito do indicativo (cf. exemplo 372 e comentário) e o presente do indicativo. Ocorre também com um adjunto adverbial que marca duração e uma perífrase durativa. São exemplos disso as frases (1.014), (1.015), (1.017), (1.018) com as perífrases de ficar e (1.051) a (1.056), (1.058) com as perífrases de permanecer.

Os adjuntos adverbiais que atuam na expressão do aspecto são quase sempre de tempo ou frequência. ${ }^{2}$ Um caso que foge a esta colocação é o do exemplo (709 b), em que a ambiguidade existente no exemplo (709 a) desaparece pela influência do adjunto adverbial de lugar "nas reuniões" que, no entanto, é facilmente convertível em adjunto adverbial de tempo.

O advérbio "já" parece sempre reforçar o perfectivo e o acabado quando utilizado com formas que marcam estes aspectos. Por outro lado, o advérbio "ainda" parece fazer o mesmo com o imperfectivo e o não acabado. Veja exemplos (1.326) e (1.327).

\subsection{Fernando já bebeu a laranjada.}

1.327. Zulmira ainda vende roupas feitas.

É comum, nas frases com “já”, a ideia de experienciamento (cf. o exemplo 84 e o exemplo 1.328 abaixo).

\subsection{Eu já andei de montanha russa.}

É interessante observar que os adjuntos adverbiais que expressam progressividade (aos poucos, pouco a pouco, cada vez mais etc.) sempre marcam (cf. exemplo 71) ou reforçam (ver exemplo 1.329 abaixo) o durativo.

1.329. Leila foi comprando o material aos poucos para depois construir a casa (perfectivo, durativo).

É importante lembrar também que os adjuntos adverbiais de frequência do tipo de sempre, todos os dias, às vezes, várias vezes, muitas vezes (e outros em "vez"), aos domingos, normalmente, diariamente, raramente,

\footnotetext{
${ }^{2}$ Bonfim (1976) afirma que advérbios como "sempre", "várias vezes", etc. são advérbios de frequência e não de tempo, com o que concordamos. (BONFIM, E. do R. M. Contribuição ao estudo do advérbio. 1976. 90 p.Tese (Livre-docência) - Departamento de Letras e Artes, Pontifícia Universidade Católica do Rio de Janeiro, Rio de Janeiro, 1976.).
} 
de tempos em tempos, em combinação com o presente e pretérito imperfeito do indicativo e do subjuntivo, levam, quase sempre, à expressão do habitual e, mais raramente, à expressão do iterativo. Vejam-se os comentários feitos sobre estes adjuntos adverbiais no item 4.2.6.

Outro tipo de relação observada entre os adjuntos adverbiais e os aspectos é que os segundos (principalmente o imperfectivo e o perfectivo) condicionam a interpretação que se pode dar aos primeiros (cf. exemplos 166 a 170 e 349 a 351 com os respectivos comentários). Há também uma seleção entre os aspectos durativo e pontual e os adjuntos adverbiais que expressam duração e pontualidade (cf. comentários no item 4.2.8). Não nos detivemos no estudo da seleção entre aspecto e adjuntos adverbiais. Fica aqui a sugestão para trabalhos futuros.

$\mathrm{O}$ adjunto adverbial também pode afetar o aspecto, na medida em que pode fazer um verbo atélico tornar-se télico (cf. comentários em torno do exemplo 96 no item 3.1).

Veja também o que comentamos no final do item 9.3.1 adiante.

\section{3 - Afixos}

Ao contrário de algumas línguas, como as eslavas, em que os afixos são de grande importância na expressão dos aspectos, o português não tem afixos que os expressem.

\subsection{1 - PREFIXOS}

Garcia (1976, p.60) afirma que o prefixo RE- marca iteração, que seria um aspecto (cf. item 1.3.7). Castilho (1967, p.61, nota 111) comenta que, a seu ver, os prefixos portugueses não indicam aspecto.

Neste ponto, estamos de acordo com Castilho. O único prefixo que poderia marcar aspecto seria RE- por expressar repetição da situação, o que caracterizaria o aspecto iterativo: reler, retransmitir, rever, etc. Entretanto não temos aqui o aspecto iterativo porque, como explicamos para as perífrases "tornar ou voltar + a + infinitivo", apesar de haver repetição da situação, os verbos formados com este prefixo se referem apenas a uma realização da situação e não lhe atribuem, portanto, uma duração descontínua. $\mathrm{O}$ aspecto destes verbos dependerá da flexão verbal e outros fatores.

Pela mesma razão exposta para o prefixo RE-, os elementos adverbiais de novo, novamente e outra vez não expressam aspecto iterativo. 


\subsection{2 - SUFIXOS}

Vários autores apontam sufixos portugueses como expressando aspecto: Luft (1976, p.131) (cf. item 1.3.5), Garcia (1976, p.60) (cf. item 1.3.7), Câmara Júnior (1974a, p.86) (cf. item 1.3.8) e Castilho (1967, p.114).

\begin{tabular}{l|l|l|l|l}
\hline & \multicolumn{1}{|c|}{ LUFT } & \multicolumn{1}{c|}{ GARCIA } & CÂMARA JR. & \multicolumn{1}{c}{ CASTILHO } \\
\hline -EJAR & iterativo & & iterativo & $\begin{array}{l}\text { inceptivo } \\
\text { incoativo, } \\
\text { iterativo }\end{array}$ \\
\hline -ITAR & iterativo & & iterativo & iterativo \\
\hline -ECER & incoativo & inceptivo & inceptivo & $\begin{array}{l}\text { inceptivo } \\
\text { incoativo, } \\
\text { inceptivo, } \\
\text { iterativo }\end{array}$ \\
\hline
\end{tabular}

São os seguintes os sufixos normalmente apresentados como marcadores de aspecto. ${ }^{3}$

incoativo $=$ inceptivo

Exemplos:

1.330. a - ejar (iterativo): voejar, gotejar.

b - ejar (inceptivo): fraquejar, palejar.

1.331. -itar (iterativo): saltitar, dormitar.

1.332. -ecer (inceptivo): amanhecer, enriquecer, endurecer.

Diz-se que os sufixos -EJAR e -ECER marcam aspecto inceptivo quando formam verbos incoativos. Já dissemos no item 2.3 que os autores fazem tal afirmação porque os verbos incoativos são verbos de situações inceptivas, isto é, situações cuja realização implica o começo de uma outra situação. Os incoativos implicam o início de um novo estado. ${ }^{4}$ Já argumentamos (cf. itens 4.2.14 e 9.1) que tais verbos não expressam aspecto inceptivo, porque, ao utilizá-los, não estamos apresentando os estados em seu momento de início ou em seus primeiros momentos, estamos

\footnotetext{
${ }^{3}$ Castilho (1.967) cita outros sufixos iterativos. Não os enumeramos, pois o raciocínio que será feito vale também para eles.

${ }^{4}$ Às vezes o verbo incoativo não marca o início de um novo estado. É o caso de "amanhecer", por exemplo.
} 
sim apresentando a situação cuja realização levará a um dado estado. Esta situação pode ter qualquer aspecto inclusive o terminativo (cf. exemplo 1.333).

1.333. A massa está terminando de endurecer. (imperfectivo, terminativo, não acabado).

Se admitíssemos que os verbos incoativos marcam aspecto inceptivo, teríamos que afirmar o mesmo do verbo "ficar" no sentido de "tornar-se, vir a estar em determinada situação" (cf. item 8.7).

Como os verbos incoativos não marcam o inceptivo ${ }^{5}$, os sufixos -EJAR e -ECER, responsáveis pela incoação, não expressam esse aspecto como normalmente se diz.

Raciocínio semelhante pode ser feito para os sufixos -EJAR e -ITAR que marcariam o iterativo. Esses sufixos e outros formam verbos que expressam situações intrinsecamente iterativas (cf. o que dizemos no item 4.2.6) e, normalmente, com ideia de diminuição. Por esta razão se diz que os sufixos formadores de tais verbos expressam aspecto iterativo. Agora perguntamos: ao usar verbos como saltitar, cuspinhar, voejar estamos nos referindo às situações de saltar, cuspir e voar atribuindo a estas uma duração descontínua limitada? É evidente que não. Estamos nos referindo a outras situações, constituídas pela repetição diminutiva destas últimas, sendo que as primeiras podem ser apresentadas ou não com aspecto iterativo, como mostramos nos exemplos (191) a (196) e como se pode ver em (1.334) e (1.335).

1.334. As borboletas estão voejando de flor em flor. (imperfectivo, cursivo, não acabado, durativo).

1.335. O filhote de que estamos tratando anda voejando e não demora a voar, indo morar com os seus na floresta. (imperfectivo, não acabado, iterativo).

Não nos parece válido pois, que, ao utilizarmos verbos como saltitar, cuspinhar, voejar e repicar, afirmemos que eles expressam aspecto iterativo, pensando na repetição de saltar, cuspir, voar e picar. Esta é, na verdade, um sema do significado daqueles verbos, o que é muito diferente de, gramaticalmente, apresentar estas últimas situações como repetidas em consequência de sua duração descontínua limitada. Assim sendo, os sufixos em questão, responsáveis por tal valor iterativo, na realidade não expressam aspecto.

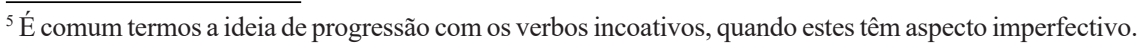




\section{4 - O TIPO ORACIONAL}

As orações podem concorrer para a expressão, alteração do aspecto ou para tornar mais patente o aspecto expresso. A maioria das orações que interferem com o aspecto são orações subordinadas adverbiais temporais, mas outros tipos podem também atuar.

Vimos que as orações temporais (normalmente iniciadas por quando, sempre que, cada vez que além de outras conjunções e locuções conjuntivas) levam o verbo ou perífrase verbal da oração em que exercem a função de adjunto adverbial a ter aspecto habitual, quando está no presente e pretérito imperfeito do indicativo e do subjuntivo. ${ }^{6}$ Para que isto ocorra, é preciso que o verbo da oração temporal esteja no presente do indicativo (se o verbo da outra estiver no presente do indicativo ou do subjuntivo) e no pretérito imperfeito do indicativo (se o verbo da outra estiver no pretérito imperfeito do indicativo ou do subjuntivo). Exemplos com verbos simples na principal podem ser observados em (1.336) a (1.339). Com perífrases verbais temos muitos exemplos no capítulo 8 (ver por exemplo, as frases 863,875 , $1.005,1.007,1.022$, 1.035, 1.038, 1.065, 1.066, 1.091, 1.092, 1.102, 1.106, 1.116, $1.169,1.170,1.198)$.

1.336. Seu primo só vem aqui, quando precisa de algo. (imperfectivo, não acabado, habitual).

1.337. Embora ele adoeça quando toma muito sol, adora ficar horas na praia. (imperfectivo, não acabado, habitual).

1.338. Minha filha chorava sempre que me via na televisão. (imperfectivo, não acabado, habitual).

1.339. Embora Marcelo me visitasse quando vinha a Uberlândia, nunca demorava mais de meia-hora. (imperfectivo, não acabado, habitual).

Quando a oração principal tem o verbo no pretérito imperfeito do indicativo ou do subjuntivo, se a oração temporal tiver o verbo no pretérito perfeito do indicativo, os aspectos cursivo e durativo, indicados por aqueles tempos, se tornam

\footnotetext{
${ }^{6}$ Castilho (1.967, p.60) observa que a iteração pode ser expressa por orações subordinadas de valor condicional temporal e apresenta o seguinte exemplo:

"Quando ela chama nós respondemos".

Nas páginas 98 a $100 \mathrm{o}$ autor apresenta outros exemplos.

Castilho vê iteração no verbo das duas orações. Parece-nos que a habitualidade está apenas no verbo da principal, que expressa uma situação cuja habitualidade está condicionada pela temporal: é habitual responder quando ela chama, mas não se expressa se é habitual ela chamar.
} 
mais patentes. Veja os exemplos (361) e (362) e comentários feitos no item 7.3 para o pretérito imperfeito do indicativo, e os exemplos (469) e (541) para o pretérito imperfeito do subjuntivo.

A exemplo dos adjuntos adverbiais, as orações adverbiais, especialmente as iniciadas pela conjunção enquanto, marcam o aspecto durativo, com o verbo nos prets. perfeito e mais-que-perfeito do indicativo. Veja exemplos (356) e (1340), (1.341) abaixo.

1.340. Samuel esperou pelo amigo até que vieram the dizer que iam fechar o bar. (perfectivo, durativo).

1.341. Conversou comigo enquanto almoçava. (perfectivo, durativo).

Vimos também que as orações adverbiais temporais podem reforçar o aspecto durativo, tornando-o mais patente, com as perífrases "ficar + gerúndio", "ficar + particípio", "ficar + por + infinitivo", "permanecer + gerúndio" e "permanecer + particípio". Veja os exemplos 1.011, 1.017, 1.024 a 1.057 nos itens 8.7 e 8.8 .

Vimos que as orações subordinadas adjetivas parecem criar uma tendência para o imperfectivo e o habitual ou o indeterminado, levando o presente e o pretérito imperfeito do subjuntivo de seus verbos a expressarem tais aspectos (cf. os exemplos 554 a 558 e os comentários feitos após os mesmos). O mesmo efeito se verifica com o presente e o pretérito imperfeito do indicativo (cf. exemplos 1.342 e 1.343 abaixo).

1.342. O homem que cumpre seu dever nada tem a temer. (imperfectivo, não acabado, habitual).

1.343. A firma que comprava nossas laranjas faliu. (imperfectivo, não acabado, habitual).

Como já foi dito, a decisão entre habitual e indeterminado é, às vezes, muito difícil.

Apesar da tendência para o habitual e o indeterminado, podemos ter o durativo nas orações adjetivas. Exemplo:

1.344. Sr. Presidente, por favor atenda as pessoas que esperam na sala. (imperfectivo, cursivo, não acabado, durativo).

Vimos também, no item 7.8.2, que nas orações adjetivas reduzidas de gerúndio, esta forma nominal expressa aspecto por influência do tipo oracional (cf. 
exemplos 622 a 625). De um modo geral, observamos que o aspecto que se pode considerar atualizado pelo gerúndio depende muito do tipo oracional em que a oração reduzida de gerúndio pode ser desenvolvida.

As orações subordinadas adverbiais proporcionais parecem reforçar o durativo expresso por suas formas verbais e pelas da oração principal (exemplos 1.345 a 1.347). Quando o verbo da principal está no pretérito perfeito ou mais-que-perfeito do indicativo a oração proporcional parece ser a responsável pelo aspecto durativo que ele possa ter. Isto parece se dar também com o próprio verbo da proporcional (exemplo 1.348).

1.345. À proporção que avançávamos, as casas iam rareando.

1.346. A inundação aumentava à medida que subiam as águas do rio.

1.347. As ânsias foram serenando à medida que tudo se esclarecia.

1.348. Seu Antônio ganhou experiência à medida que envelheceu e não de uma hora para outra, como você quer. (perfectivo, durativo).

Isto se dá sempre que temos orações proporcionais. É interessante notar que nas orações proporcionais existe uma tendência para apresentar o verbo, seu e da principal, no presente e no pretérito imperfeito do indicativo. Isto talvez se explique pelo valor progressivo apresentado por este tipo de oração e que é mais natural com tais tempos flexionais.

O iterativo pode ser marcado pelas orações coordenadas alternativas com ora...ora em frases como (1.349) a (1.351).

1.349. José ora se entristecia, ora se alegrava sem motivo aparente para tais mudanças.

1.350. As crianças ora choram, ora brincam; mas não dão muito trabalho.

1.351. Ora você o odiará, ora o amará, pois em determinados momentos ele é um demônio, noutros um anjo.

Em frases com o verbo no presente do indicativo (como 1.350), parece que temos o habitual e não o iterativo simples.

Castilho (1.967, p.100) anota que o predicado composto ligado por e parece exercer influência na expressão da repetição e apresenta os seguintes exemplos:

1.352. "O menino mais velho, passada a primeira vertigem, [...] adormecia e acordava". - (G. Ramos) 
1.353. Vedes, além, na Estrada de Santiago, aquela estrelinha a luzir e a apagar-se como candeia ao vento?" - (A. Ribeiro)

Realmente temos aspecto iterativo nos dois casos, mas este se deve antes ao sentido alternativo que há na construção do que a ela em si, pois, se tivermos esse "predicado composto" sem o sentido alternativo, não teremos o iterativo, como se pode ver em (1.354).

1.354. Quando entrei no escritório, Celso almoçava e lia o jornal para não perder tempo. (imperfectivo, cursivo, não acabado, durativo - para os dois verbos).

\section{5 - A REPETIÇÃo do Verbo}

Como vimos no item 7.3, a repetição do verbo no pretérito perfeito do indicativo marca o aspecto durativo, a exemplo do que ocorre nas frases (139), (140), (265), (357) e (1.355) abaixo, em que o verbo é repetido com "que" intermediário.

1.355. "E foram que foram, andaram que andaram e chegaram na casa do pai de São Francisco.” - (O. E. Xidieh $)^{7}$ (perfectivo, durativo).

A repetição do verbo pode marcar o durativo também com outros tempos flexionais. Exemplos:

1.356. O menino correra, correra e depois ficara à sombra de uma árvore descansando.

1.357. Você trabalhará, trabalhará para no fim não ter nada.

1.358. Mesmo que pensasse, pensasse e pensasse, não conseguiria saber o que fazer.

Com o verbo no presente e pretérito imperfeito do subjuntivo e principalmente do indicativo, é comum ter-se o habitual. Neste caso, a situação que se repete é vista como durativa. Exemplos:

\footnotetext{
${ }^{7}$ Exemplo apud Castilho (1.967, p.72). Castilho apresenta este exemplo e uma série de outros com o verbo repetido, entre os exemplos de frases com aspecto Imperfectivo Cursivo Propriamente Dito. Para ele a repetição do verbo é apenas um recurso de ampliação da duração, mas não um recurso de expressão de qualquer aspecto.
} 
1.359. Você fala, fala, fala; mas na hora de agir não faz nada.

1.360. Toda noite ele lia, lia, lia e só bem tarde é que ia dormir.

Observe-se que o verbo repetido expressa também uma certa intensificação da situação.

Castilho (1.967, p.96, § 87a, nota 138) observa que a iteração pode ser expressa pela repetição do verbo, e que exemplos como o de IMBS (1.960, p.55) (cf. exemplo 1.361), em que o futuro expressa repetição, devem ser explicados, dizendo que o futuro repetido expressa iteração e não o futuro em si.

1.361. "Je leur ai donné mon pain: la belle avance! Ils auront faim ce soir, ils auront faim demain!". 8

Castilho, à mesma página, dá o seguinte exemplo:

1.362. "Pois é, Sr. Doutor, meu irmão, bato-lhe à mesma. Bato na mulher, bato na criança, bato no cão." - V. Ferreira.

E diz que aí teríamos aspecto iterativo devido à repetição do verbo. Temos certa reserva em aceitar tal colocação, pois nos parece que tal repetição não marca aspecto iterativo nem numa frase como a da nota 149, resultante da tradução de (1.361), nem em (1.362). Nesta, considerando que o presente do indicativo não tenha valor de futuro no contexto em que se achava a frase, temos aspectos imperfectivo, não acabado e habitual, para cada ocorrência do verbo bater, mas aí o habitual se deve não à repetição do verbo, mas ao presente do indicativo. Pode-se verificar que a habitualidade não se deve à repetição do verbo confrontando-se o exemplo anterior com (1.363).

1.363. Sim, doutor, eu bato na minha mulher. (imperfectivo, não acabado, habitual).

\section{6 - ÊNFASE ENTONACIONAL}

Como vimos no item 7.3, os verbos estáticos (entre eles os de estado) e os verbos atélicos, no pretérito imperfeito do indicativo, marcam o aspecto acabado, quando, na língua falada, são enfatizados entonacionalmente dentro da frase.

\footnotetext{
8 "Eu lhes dei meu pão: grande vantagem! Eles terão fome esta noite, eles terão fome amanhã!"
} 


\section{7 - Preposições}

Em alguns casos, as preposições parecem influir na expressão de certas noções aspectuais e mesmo ser responsáveis pela atualização da categoria em outros.

A preposição A, quando utilizada com o infinitivo, parece ser a responsável pelos aspectos imperfectivo, cursivo, não acabado e durativo em casos como os exemplificados em (1.364 a), (1.365 a), (1.367) e (1.368). Em alguns casos, dependendo do verbo, temos o iterativo no lugar do cursivo e do durativo (como em 1.366a). Observando (1.364 b) a (1.366 b), em que a preposição foi retirada, vemos que a noção aspectual desapareceu, o que parece confirmar que é a preposição a responsável por sua presença nas frases a. Nas frases b, temos só a ideia de futuro.

1.364. a - Vou a ler o livro pelo caminho..$^{9}$ (imperfectivo, cursivo, não acabado, durativo).

b - Vou ler o livro pelo caminho. (futuro).

1.365. a - José ia pela rua a pensar no problema, quando o chamaram. (imperfectivo, cursivo, não acabado, durativo).

b - José ia pensar no problema, quando o chamaram. (futuro iminência de ação).

1.366. a - Vou a perguntar por meu filho. (imperfectivo, não acabado, iterativo).

b - Vou perguntar por meu filho. (futuro).

1.367. A falar ele entrou na sala. (imperfectivo, cursivo, não acabado, durativo).

1.368. Quando cheguei em casa encontrei-o a beber. (imperfectivo, cursivo, não acabado, durativo).

Além destes casos, observando as perífrases que diferem apenas pela preposição que entra na sua formação, podemos dizer que, de alguma forma, essas preposições são responsáveis ou pelo menos influenciam nas diferenças aspectuais entre tais perífrases e, consequentemente, têm algo a ver com o aspecto expresso pelo todo da perífrase. Podemos observar o que se acabou de dizer comparando, por exemplo, os pares de perífrases especificadas em (1.369).

\footnotetext{
${ }^{9}$ IR + A + INFINITIVO não constitui uma perífrase, por isso não foi estudada no item 8.4. Na verdade, o que temos é o verbo ir indicando locomoção e "a + infinitivo" indicando a forma de locomoção (se o verbo é de movimento), ou o que se faz concomitantemente à locomoção. Os falantes no Brasil parecem preferir a construção com o gerúndio, tanto neste caso como no exemplificado nas frases (1367) e (1368)
} 
1.369. a - estar $+\mathrm{a}+$ infinitivo e estar + por + infinitivo.

$\mathrm{b}-\operatorname{vir}+\mathrm{a}+$ infinitivo e vir + de + infinitivo.

$\mathrm{c}$ - continuar $+\mathrm{a}+$ infinitivo e continuar + por + infinitivo.

$\mathrm{d}-$ acabar + de + infinitivo e acabar + por + infinitivo.

e - terminar $+\mathrm{de}+$ infinitivo e terminar + por + infinitivo.

A diferença entre as perífrases de $\mathbf{b}, \mathbf{d}$ e e não são propriamente aspectuais, mas para aquelas que atuam na expressão do aspecto vale o que foi dito anteriormente, pois, por exemplo, a preposição de deve ter algo a ver com o fato de "acabar ou terminar + de + infinitivo" poderem expressar o terminativo e "acabar ou terminar + por + infinitivo" não poderem.

Finalmente, observando as perífrases "estar, ficar ou continuar + por + infinitivo" e frases como (1.370), em que temos apenas "por + infinitivo", podemos dizer que a preposição por ao lado do infinitivo é a principal, senão a única responsável pela expressão do aspecto não começado no Português.

\subsection{Ainda há vários espécimes por catalogar.}

Em frases como (1.370), o "por + infinitivo" pode ser considerado como uma oração reduzida desdobrável em uma oração adjetiva com a perífrase "estar + por + infinitivo" (ver exemplo 1.371).

\subsection{Ainda há vários espécimes que estão por catalogar.}

Já dissemos que "por + infinitivo" tem sempre o valor de um atributo. A este respeito veja-se o que diz Dias (1.970, p.231-232).

\section{8 - O COMPLEMENTO E O SUJEITO DO VERBO}

Castilho (1.967, p.59) afirma que diversos contrastes aspectuais podem ser marcados pelo complemento do verbo. Segundo ele, é normal que um complemento no plural leve o verbo a expressar o aspecto iterativo. $\mathrm{O}$ autor apresenta os exemplos (1.372) a (1.374) a que acrescentamos (1.375).

1.372. "Casou-se com um grande costureiro, o mais bonito de todos eles, que desenhava todos os seus vestidos de noiva". - (A. Moniz)

1.373. "O marido é um banana [...]. A mulher deu nele uns gritos." (Lins do Rego) 
1.374. "Passou depois por mim o tropel da vida e da morte, assisti a muitos fatos históricos”. - (R. Brandão)

1.375. O rapaz pulou os obstáculos.

Seguindo este tipo de pensamento, podemos dizer que, quando o complemento individualiza cada componente de um grupo, o verbo passa a expressar o iterativo. Exemplo:

\subsection{Bati em cada porta da rua.}

Efeito semelhante ocorre também quando o sujeito individualiza cada componente de um grupo. Confronte o exemplo (1.377) em que não há iteratividade, com o exemplo (1.378) onde haveria iteração.

1.377. Os alunos da classe bateram o sino.

1.378. Cada aluno da classe bateu o sino.

A nosso ver, esse possível efeito do complemento e do sujeito no aspecto expresso é discutível, pois, embora "saibamos" que na realidade as situações de desenhar, dar, assistir, pular e bater se repetem, a frase parece não indicar, explicitamente, a ideia de repetição que é mais logicamente deduzida do que marcada gramaticalmente.

Resta-nos dizer que os complementos do verbo podem influir no aspecto expresso, na medida em que podem fazer um verbo atélico tornar-se télico (cf. no item 3.1 os comentários em torno dos exemplos 95 e 96), pois, como vimos, o fato de o verbo ser télico ou atélico pode modificar o aspecto expresso por um dado recurso. Esta seria uma influência indireta do complemento do verbo no aspecto expresso pelo mesmo.

Temos também o efeito do objeto e do sujeito singular ou plural na estruturação e aceitabilidade de frases construídas com certas perífrases iterativas, embora não estejam influindo no aspecto (cf. exemplos em 8.2.1, 8.5.4, 8.6.1 e 8.6.2).

É comum o sujeito de uma frase com aspecto indeterminado ter sentido genérico, mas não é o sentido genérico do sujeito que leva o verbo a ter aspecto indeterminado. Ao contrário, é o aspecto indeterminado que leva o sujeito a ter tal valor. Comparem-se as frases (1.379) e (1.380).

1.379. Os gatos têm sete vidas. (imperfectivo, não acabado, indeterminado) (sujeito com sentido genérico).

1.380. Os gatos estão miando. (imperfectivo, cursivo, não acabado, durativo) (o sujeito não tem valor genérico). 